\title{
Measurement of Internal Jugular Vein and Common Carotid Artery Diameter Ratio by Ultrasound to Estimate Central Venous Pressure
}

Sheher Bano ${ }^{1}$, Aayesha Qadeer ${ }^{2}$, Aftab Akhtar ${ }^{1}$, Hafiz Muhammad Ata ur-Rehman ${ }^{1}$, Kamran Munawar ${ }^{3}$, Syed Waqar Hussain ${ }^{4}$, Muhammad Tariq Khan ${ }^{5}$, Rizwan Zafar 6

1. Internal Medicine, Shifa International Hospital, Islamabad, PAK 2. Critical Care, Shifa International Hospital, Islamabad, PAK 3. Internal Medicine, Shifa College of Medicine, Islamabad, PAK 4. Internal Medicine, Khan Research Laboratories Hospital, Islamabad, PAK 5. Pulmonology, Shifa International Hospital, Islamabad, PAK 6. Department of Internal Medicine, Shifa International Hospital, Islamabad, PAK

$\square$ Corresponding author: Rizwan Zafar, rzafar9@gmail.com

Disclosures can be found in Additional Information at the end of the article

\section{Abstract}

\section{Objective}

The objective of this study is to find a correlation between internal jugular vein (IJV) and common carotid artery (CCA) diameter ratio and central venous pressure (CVP) measurement and find a cut-off value for the IJV/CCA ratio to predict low CVP i.e. $<10 \mathrm{~cm} \mathrm{H}_{2} 0$, for estimating the volume status in critically ill patients.

\section{Methods}

This prospective cross-sectional study was conducted at the critical care department of Shifa International Hospital, Islamabad, from July to December 2017. A sample of 49 patients $\geqslant 18$ years with intrathoracic central venous catheters (CVCs) who underwent bedside sonographic assessments of IJV and CCA diameter were included in this study using convenient sampling. The IJV/CCA diameter ratio was calculated and correlated with CVP and the predictive value of the IJV/CCA diameter ratio to predict CVP $<10 \mathrm{~cm} \mathrm{H}_{2} \mathrm{O}$ was explored by calculating the area under the receiver operating characteristic (ROC) curve, sensitivity, specificity, and positive and negative predictive values.

\section{Results}

Received 02/15/2018 Review began $02 / 20 / 2018$ Review ended 03/02/2018 Published 03/05/2018

\section{(C) Copyright 2018}

Bano et al. This is an open access article distributed under the terms of the Creative Commons Attribution License CC-BY 3.0., which permits unrestricted use, distribution, and reproduction in any medium, provided the original author and source are credited.
A total of 49 patients, 30 males (61.2\%) and 19 females (38.8\%) with a mean age of $56.00 \pm 16.11$ years were included in the study. The mean CVP was $8.98 \pm 2.37 \mathrm{~cm} \mathrm{H}_{2} \mathrm{O}$ in ventilated (51\%) and $10.7 \pm 6.01 \mathrm{~cm} \mathrm{H}_{2} \mathrm{O}$ in non-ventilated (49\%) patients. The mean IJV/CCA diameter ratio was $1.60 \pm 0.55$ at expiration and $1.41 \pm 0.56$ at inspiration. There was a significant correlation between the IJV/CCA diameter ratio and CVP at expiration ( $r=0.401, p=0.004)$. The correlation between IJV/CCA and CVP was significant in non-ventilated patients at expiration ( $\mathrm{r}=0.439$, $\mathrm{p}=0.032$ ). The area under the ROC curve for the IJV/CCA diameter ratio for predicting CVP $<10$ $\mathrm{cm} \mathrm{H}_{2} \mathrm{O}$ was 0.684 ( $\mathrm{p}=0.028$ ). The predictive value of the IJV/CCA diameter ratio for $\mathrm{CVP}<10$ $\mathrm{cm} \mathrm{H}_{2} \mathrm{O}$ at the cutoff value of $<2$ was insignificant. A new cut-off $<1.75$ was taken for the IJV/CCA diameter ratio from the coordinates of the ROC curve. The sensitivity, specificity, PPV, 
and NPV of an IJV/CCA diameter ratio of $<1.75$ for predicting a CVP $<10 \mathrm{~cm} \mathrm{H}_{2} 0$ were $84.62 \%$, $52.17 \%, 66.67 \%$, and $75.00 \%$, respectively.

\section{Conclusion}

The assessment of volume status by the IJV/CCA diameter ratio with a sonographic device may be a useful noninvasive alternative for a central venous catheterization with a cut-off $<1.75$.

Categories: Internal Medicine, Pulmonology

Keywords: central venous pressure, common carotid artery, internal jugular vein, volume status, critically ill patient

\section{Introduction}

A bedside assessment of volume status is a crucial part of patient management in critically ill patients [1]. There are different invasive and noninvasive methods for volume assessment. The commonly used invasive parameters for volume assessment are pulmonary artery catheter (PAC) and central venous pressure (CVP). However, PAC use is becoming obsolete these days due to studies showing increased mortality with PAC placement [2]. More than $90 \%$ of intensivists use CVP to guide fluid management [3]. Some of the noninvasive modalities for volume status assessment include an ultrasonographic assessment of the inferior vena cava (IVC) collapsibility index, internal jugular or femoral vein collapsibility, and internal jugular vein/common carotid artery cross-section area [4-8].

Point of care ultrasonography is getting more importance these days in patient management, especially in emergency and intensive care units due to fewer complications [9]. Complications associated with central venous pressure (CVP) insertion include pneumothorax, bleeding and arterial punctures, the risk of local and distant infections, such as insertion site infections and catheter-related bloodstream infections, and septic emboli [4]. The IVC collapsibility index assessment by ultrasound is a convenient method for assessing volume status, but this modality is difficult to use in patients with recent abdominal surgeries, abdominal wounds, morbid obesity, and raised intra-abdominal pressure [5].

Recently, internal jugular vein (IJV) and common carotid artery (CCA) ratio measurement using ultrasound is found to be effective for CVP estimation. Najed et al. reported a significant positive correlation between the CVP and IJV/CCA ratio $(r=0.734, p<0.05)$. Sensitivity, specificity, and the positive and negative predictive value of the IJV/CCA diameter ratio for CVP estimation were $90 \%, 86.36 \%, 90 \%$, and $86.36 \%$, respectively [6]. Hilbert et al. reported that the IJV/CCA ratio using ultrasound is an effective non-invasive alternative for CVP measurement among critically ill patients [10]. Baily et al. found that an IJV/CCA ratio $\geqslant 2$ is significantly associated with a CVP $>8 \mathrm{mmHg}(\mathrm{p}<0.05)[11]$.

To look for a reliable, noninvasive convenient method for volume status assessment in critically ill patients, we conducted this study in our non-western population, where we tried to find a correlation between the IJV/CCA diameter ratio and CVP measurement and to find a cut-off ratio for the IJV/CCA diameter ratio and low CVP i.e. $<10 \mathrm{~cm} \mathrm{H20.}$

\section{Materials And Methods}

This prospective cross-sectional study was conducted at the critical care department of Shifa International Hospital, Islamabad. The study was approved by the ethics and review board of Shifa International Hospital, Islamabad. It was conducted from July 2017 to December 2017. Informed consent was taken from the patients or their family members when patients were 
unable to consent for themselves. Patients were enrolled from the medical and surgical intensive care units. The inclusion criteria consisted of all patients $\geqslant 18$ years of age admitted in the critical care area of the hospital and having an intrathoracic central venous catheter (CVC) in place for producing a CVP waveform through the transducer. Patients with pulmonary hypertension, any type of defect at the site of sonology, tricuspid regurgitation, inability to lay supine, instability of vital signs during sonography, and unwillingness to participate were excluded.

Sonographic assessments were performed by critical care fellows. They were formally trained and were given an orientation for the procedures protocol to minimize operator-related bias. It was followed by a practice examination under the critical care consultants and supervisors. The linear probe of the Mindray diagnostic ultrasound system, model Z6 (Mindray, South Carolina, USA) was used. Patients were placed in the supine position at the level of the bed with no pillow or other objects under the head. All measurements were obtained at the level of the cricoid cartilage. The first ultrasound gel was applied to the side of the neck. A vascular transducer was then placed lightly on the neck and manual pressure was used to compress the IJV, distinguishing it from the CCA. IJV measurements were performed both at the end of inspiration and of expiration.

CVP was measured immediately after the sonographic examination. It was measured manually using a pressure manometer from the distal lumen of the central venous catheter and a singlelead electrocardiogram strip. The zero point was taken at the level of the fourth intercostal space in the mid-axillary line to represent the level of the right atrium. CVP was measured from a recording at the end of expiration, with the patient supine. The sonographers were blinded to the CVP readings. Patients were divided into two groups based on a CVP cutoff point of $10 \mathrm{~cm}$ $\mathrm{H} 2 \mathrm{O}$ (about $7 \mathrm{mmHg}$ ), which is the recommended threshold for predicting volume responsiveness [12-13].

\section{Data analysis}

The sample size was calculated as 49 using the World Health Organization (WHO) sample size calculator, taking the $5 \%$ level of significance, $80 \%$ power, mean value of IJV/CCA ratio 1.89 , and SD 0.83 reported in the previous study by Nejad et al. [6].

All the data was entered and analyzed using SPSS version 21.0 (IBM, NY, USA). Results were presented as mean $\pm \mathrm{SD}$ for quantitative variables and relative frequencies (percentages) for categorical variables. The normal distribution of quantitative variables was assessed using the Shapiro-Wilk test and Q-Q plots. The independent t-test was used to investigate the probability of significance of the differences of quantitative variables between two groups. The paired t-test and $\chi 2$ or Fisher's exact test used for the assessment of the significance of the differences of two quantitative variables and categorical variables, respectively. Correlations were done to test for linear relations between the IJV/CCA ratio and CVP by the Pearson correlation coefficient. Sensitivity, specificity, and positive and negative predictive values (PPV and NPV), as well as positive and negative likelihood ratios with 95\% confidence interval (CI), were calculated. The diagnostic performance of the IJV/CCA diameter ratio was expressed as the area under the receiver operating characteristic (ROC) curve. A p value of $<0.05$ was considered significant.

\section{Results}

A total of 49 patients, 30 males (61.2\%) and 19 females (38.8\%), with a mean age of $56.00 \pm 16.11$ years, were included in the study from July to December 2017. The mean CVP was $9.87 \pm 4.57 \mathrm{~cm}$ $\mathrm{H}_{2} \mathrm{O}$ (95\% CI: 8.55 - 11.18). Among 49 patients, CVP was $<10 \mathrm{~cm} \mathrm{H}_{2} \mathrm{O}$ in 26 (53.1\%) and $\geqslant 10$ $\mathrm{cm} \mathrm{H}_{2} \mathrm{O}$ in 23 (47\%). There were 25 (51\%) ventilated and 24 (49\%) non-ventilated patients. 


\section{Cureus}

There was no significant difference in demographic data (Table 1).

\begin{tabular}{|c|c|c|c|c|}
\hline Patients Included, n & 49 & $\begin{array}{l}\text { Mechanical ventilation } \\
\text { Yes } 25(51 \%)\end{array}$ & $\begin{array}{l}\text { Mechanical ventilation } \\
\text { No } 24(49 \%)\end{array}$ & $\begin{array}{l}p- \\
\text { value }\end{array}$ \\
\hline Male, n (\%) & $30(61.2 \%)$ & $13(52 \%)$ & $17(70.8 \%)$ & 0.176 \\
\hline Female, n (\%) & $19(38.8 \%)$ & $12(48 \%)$ & $7(29.2 \%)$ & \\
\hline Age, mean \pm SD $(95 \% \mathrm{Cl})$, years & $56.00 \pm 16.11$ & $57.0 \pm 13.58$ & $54.96 \pm 18.63$ & 0.662 \\
\hline $\begin{array}{l}\text { CVP, mean } \pm \text { SD }(95 \% \mathrm{Cl}), \mathrm{cm} \\
\mathrm{H}_{2} \mathrm{O}\end{array}$ & $\begin{array}{l}9.87 \pm 4.57(95 \% \mathrm{Cl}: \\
8.55-11.18)\end{array}$ & $8.98 \pm 2.37$ & $10.79 \pm 6.01$ & 0.169 \\
\hline $\begin{array}{l}\text { IJV diameter expiratory, mean } \pm \\
\text { SD }(95 \% \mathrm{Cl}), \mathrm{cm}\end{array}$ & $\begin{array}{l}1.15 \pm 0.41(95 \% \mathrm{Cl}: \\
1.029-1.267)\end{array}$ & $\begin{array}{l}1.16 \pm 0.36(95 \% \mathrm{Cl}: \\
1.01-1.30)\end{array}$ & $\begin{array}{l}1.14 \pm 0.47(95 \% \mathrm{Cl}: \\
0.94-1.33)\end{array}$ & 0.838 \\
\hline $\begin{array}{l}\text { IJV diameter inspiratory, mean } \pm \\
\text { SD }(95 \% \mathrm{CI}), \mathrm{cm}\end{array}$ & $\begin{array}{l}1.1 \pm 0.41(95 \% \mathrm{Cl}: \\
0.89-1.13)\end{array}$ & $\begin{array}{l}1.07 \pm 0.41(95 \% \text { Cl: } \\
0.90-1.23)\end{array}$ & $\begin{array}{l}0.96 \pm 0.41(95 \% \mathrm{Cl}: \\
0.78-1.13)\end{array}$ & 0.362 \\
\hline $\begin{array}{l}\text { CCA diameter, mean } \pm \text { SD }(95 \% \\
\mathrm{CI}), \mathrm{cm}\end{array}$ & $\begin{array}{l}0.72 \pm 0.10(95 \% \mathrm{Cl}: \\
0.69-0.75)\end{array}$ & $\begin{array}{l}0.73 \pm 0.09(95 \% \mathrm{Cl}: \\
0.69-0.78)\end{array}$ & $\begin{array}{l}0.70 \pm 0.11(95 \% \mathrm{Cl}: \\
0.66-0.75)\end{array}$ & 0.316 \\
\hline
\end{tabular}

\section{TABLE 1: Patients' characteristics}

CVP: central venous pressure, IJV: internal jugular vein, CCA: common carotid artery, SD: standard deviation, Cl: confidence interval

\section{Assessment of IJV}

The mean IJV diameter was $1.15 \pm 0.41 \mathrm{~cm}(95 \% \mathrm{CI}: 1.029-1.267)$ at expiration and $1.01 \pm 0.41$ cm (95\% CI: $0.89-1.13)$ at inspiration. There was no significant difference between ventilated and non-ventilated patients ( $\mathrm{p}=0.838$ at expiration, $\mathrm{p}=0.362$ at inspiration) (Table 1 ). There was a significant correlation between IJV diameter and CVP $(r=0.472, n=49$, $p$-value $=0.001$ at expiration and $\mathrm{r}=0.348, \mathrm{n}=49, \mathrm{p}=0.014$ at inspiration). The correlation was not significant in ventilated patients $(\mathrm{r}=0.386, \mathrm{n}=25, \mathrm{p}=0.057$ at expiration and $\mathrm{r}=0.383, \mathrm{n}=25, \mathrm{p}=0.058$ at inspiration). In non-ventilated patients, the association was significant $(r=0.544, n=24, p=$ 0.006 at expiration and $\mathrm{r}=0.434, \mathrm{n}=24, \mathrm{p}=0.034$ at inspiration) (Table 2). 


\section{Cureus}

\begin{tabular}{|l|llllll|}
\hline Correlation between & \multicolumn{2}{l}{ Total (49) } & \multicolumn{2}{l|}{ Mechanical ventilation Yes (25) } & \multicolumn{2}{l|}{ Mechanical ventilation No (24) } \\
\hline & r-value & p-value & r-value & $p$-value & r-value & p-value \\
IJV (exp) with CVP & 0.472 & 0.001 & 0.386 & 0.057 & 0.544 & 0.006 \\
IJV (insp) with CVP & 0.348 & 0.014 & 0.383 & 0.058 & 0.434 & 0.034 \\
CCA with CVP & 0.281 & 0.051 & 0.046 & 0.826 & 0.447 & 0.029 \\
IJV (exp)/CCA with CVP & 0.401 & 0.004 & 0.343 & 0.094 & 0.439 & 0.032 \\
IJV (insp)/CCA with CVP & 0.275 & 0.056 & 0.346 & 0.090 & 0.308 & 0.143 \\
\hline
\end{tabular}

TABLE 2: Correlations between IJV diameter (at end expiration and end inspiration) and IJVICCA (at end inspiration and end expiration) with CVP

IJV: internal jugular vein, CCA: common carotid artery, CVP: central venous pressure

\section{Assessment of CCA}

The mean CCA diameter was $0.72 \pm 0.10 \mathrm{~cm}(95 \% \mathrm{CI}: 0.69-0.75)$. There was no significant difference between ventilated and non-ventilated patients $(\mathrm{p}=0.316)($ Table 1$)$. There was no significant correlation between CCA diameter and CVP $(r=0.281, n=49, p=0.051)$.

\section{Assessment of IJV/CCA ratio}

The mean IJV/CCA diameter ratio was $1.60 \pm 0.55$ (95\% CI: $1.44-1.75$ ) at expiration and $1.41 \pm 0.56$ (95\% CI: 1.24-1.57) at inspiration. There was a significant correlation between the IJV/CCA diameter ratio and CVP at expiration $(\mathrm{r}=0.401, \mathrm{n}=49, \mathrm{p}=0.004)$ and a non-significant correlation at inspiration $(\mathrm{r}=0.275, \mathrm{n}=49, \mathrm{p}=0.056$ ) (Figure 1$)$. The correlation between the IJV/CCA diameter ratio and CVP was non-significant in ventilated patients at both inspiration and expiration $(\mathrm{r}=0.343, \mathrm{n}=25, \mathrm{p}=0.094$ and $\mathrm{r}=0.346, \mathrm{n}=25, \mathrm{p}=0.094$, respectively). The correlation between the IJV/CCA diameter ratio and CVP was significant in non-ventilated patients at expiration $(\mathrm{r}=0.439, \mathrm{n}=24, \mathrm{p}=0.032)$ and was non-significant at inspiration $(\mathrm{r}=$ $0.308, \mathrm{n}=24, \mathrm{p}=0.143$ ) (Table 2).

The mean IJV/CCA ratio at expiration at CVP $<10 \mathrm{~cm} \mathrm{H}_{2} \mathrm{O}$ was $1.39 \pm 0.50$, and it was $1.83 \pm 0.52$ at $\mathrm{CVP} \geqslant 10 \mathrm{~cm} \mathrm{H}_{2} \mathrm{O}$ with $\mathrm{p}=0.004$. The mean IJV/CCA ratio at inspiration at CVP $<10 \mathrm{~cm} \mathrm{H}_{2} \mathrm{O}$ was $1.23 \pm 0.53$, and it was $1.60 \pm 0.55$ at $\mathrm{CVP} \geqslant 10 \mathrm{~cm} \mathrm{H}_{2} \mathrm{O}$ with $\mathrm{p}=0.022$ (Table 3). 


\section{Cureus}
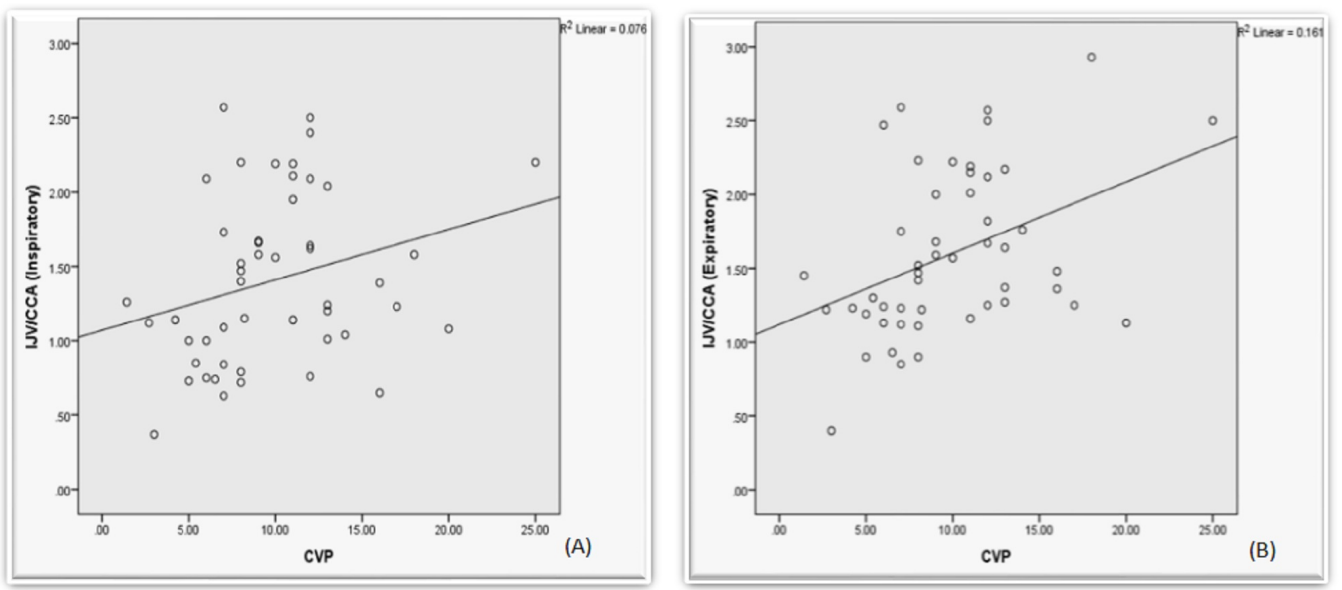

FIGURE 1: Relationship between central venous pressure (CVP) and internal jugular vein and common carotid artery (IJV/CCA) diameter ratio at inspiration (A) and at expiration (B).

\begin{tabular}{|c|c|c|c|}
\hline & CVP $<10 \mathrm{~cm} \mathrm{H} \mathrm{H}_{2} \mathrm{O}$ & $C V P \geq 10 \mathrm{~cm} \mathrm{H}_{2} \mathrm{O}$ & p-value \\
\hline & $\mathrm{n}=26$ & $\mathrm{n}=23$ & \\
\hline CCA Diameter & $0.70 \pm 0.01$ & $0.74 \pm 0.11$ & 0.173 \\
\hline IJV Diameter (exp) & $0.97 \pm 0.36$ & $1.34 \pm 0.39$ & 0.001 \\
\hline IJV Diameter (insp) & $0.87 \pm 0.38$ & $1.18 \pm 0.39$ & 0.007 \\
\hline IJV $(\exp ) / C C A$ & $1.39 \pm 0.50$ & $1.83 \pm 0.52$ & 0.004 \\
\hline IJV (insp)/CCA & $1.23 \pm 0.53$ & $1.60 \pm 0.55$ & 0.022 \\
\hline
\end{tabular}

TABLE 3: Comparison of the diameter of common carotid artery (CCA) and internal jugular vein (IJV) at inspiration and expiration between patients with a central venous pressure (CVP) $<10$ or $\geq 10 \mathrm{~cm} \mathrm{H} 2 O$

The predictive value of the IJV/CCA diameter ratio for CVP $<10 \mathrm{~cm} \mathrm{H2O}$ at cutoff $<26$ was found to be insignificant. The area under the ROC curve for the IJV/CCA diameter ratio was 0.640 (95\% CI: 0.482 - 0.799), p-value > 0.05.The area under ROC curve for IJV/CCA diameter ratio for predicting CVP $<10 \mathrm{~cm} \mathrm{H2O}$ was $0.748, \mathrm{p}=0.003$ (Figure 2). A new cut off value $<1.75$ was taken for IJV/CCA diameter ratio from the coordinates of the ROC curve. The sensitivity, specificity, PPV and NPV of an IJV/CCA diameter ratio of $<1.75$ for predicting a CVP $<10 \mathrm{~cm}$ $\mathrm{H} 2 \mathrm{O}$ were $84.62 \%, 52.17 \%, 66.67 \%$ and $75.00 \%$ respectively. The positive likelihood ratio and the negative likelihood ratio were 1.77 and 0.29 , respectively. The area under the ROC curve for the IJV/CCA diameter ratio for predicting CVP < $10 \mathrm{~cm} \mathrm{H}^{2} \mathrm{O}$ was 0.684 (95\% CI: 0.531-0.837, $\mathrm{p}=$ 0.028) (Table 4). 


\section{Cureus}

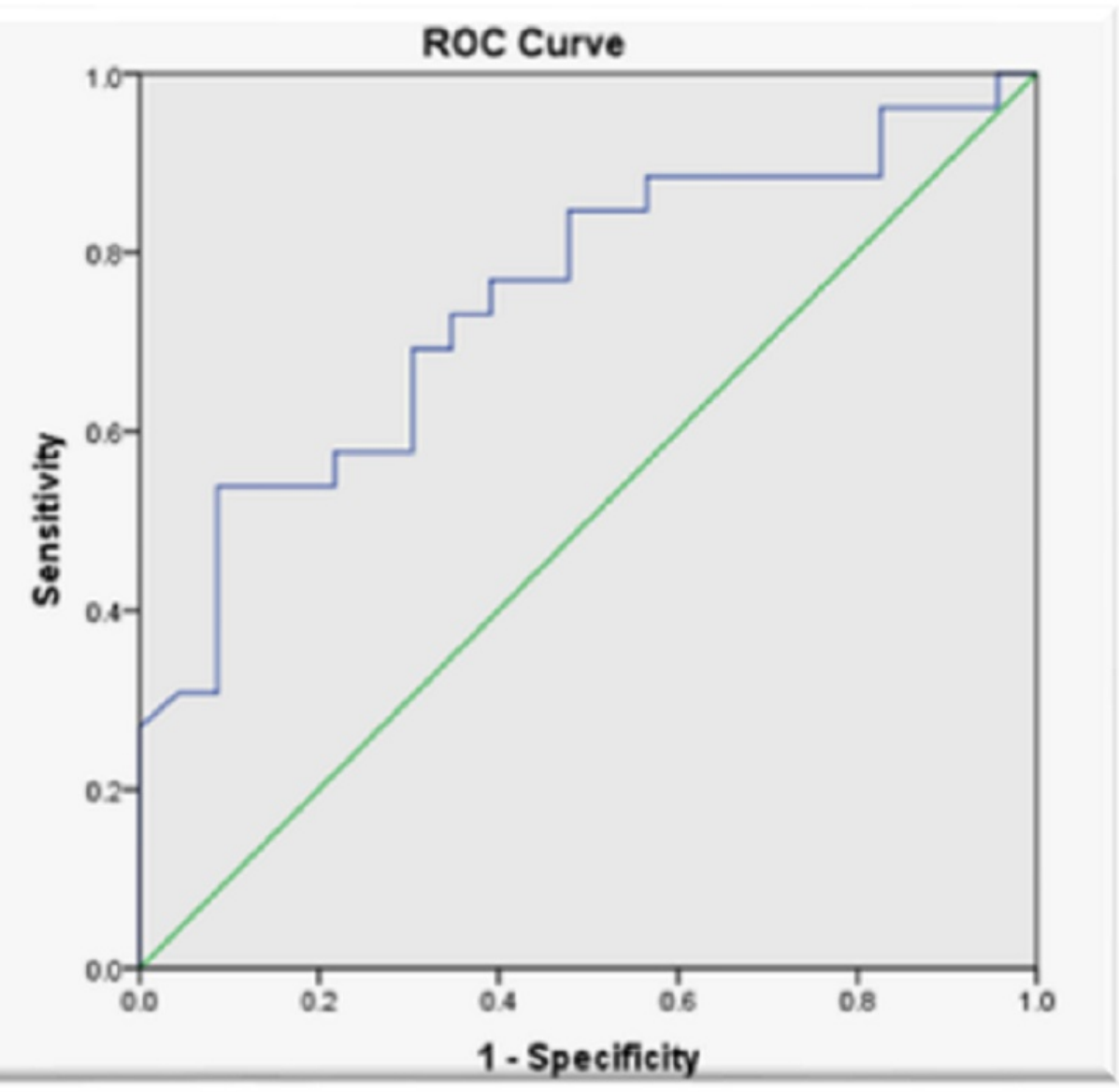

FIGURE 2: Receiver operating characteristic (ROC) curve for internal jugular vein/common carotid artery (IJV/CCA) ratio in predicting a central venous pressure (CVP) $<10 \mathrm{~cm} \mathrm{H2O} \mathrm{(area}$ under the curve $\mathbf{0} \mathbf{0 . 7 4 8}$ ) 


\section{Cureus}

\begin{tabular}{|c|c|c|c|}
\hline \multirow[b]{2}{*}{ |JV/CCA Ratio <1.75 } & \multicolumn{2}{|c|}{ Central Venous Pressure $<10 \mathrm{~cm} \mathrm{H}_{2} \mathrm{O}$} & \multirow[b]{2}{*}{ Total } \\
\hline & Positive & Negative & \\
\hline Positive & 22 & 12 & 34 \\
\hline Negative & 4 & 11 & 15 \\
\hline Total & 26 & 23 & 49 \\
\hline Sensitivity = 84.62\% & PPV $=66.67 \%$ & Positive lik & \\
\hline Specificity = 52.17\% & $N P V=75.00 \%$ & Negative li & \\
\hline
\end{tabular}

TABLE 4: Sensitivity, specificity, positive predictive value (PPV), negative predictive value (NPV), and positive and negative likelihood ratios of internal jugular vein/common carotid artery (IJV/CCA) for central venous pressure

\section{Discussion}

This study aimed to evaluate the IJV/CCA diameter ratio by ultrasound to estimate central venous pressure as a non-invasive tool for volume assessment. The current study showed that there is a moderate correlation of the IJV/CCA diameter ratio at expiration with CVP $(\mathrm{r}=0.401)$, there is a poor correlation in patients who are on the ventilator $(r=0.343)$. Cutoff $<2$ for the IJV/CCA diameter, as reported by Nejad et al. [6], showed a significant result for predicting a CVP $<10 \mathrm{~cm} \mathrm{H}_{2} \mathrm{O}$. Our cut-off values of $<2$ showed insignificant results ( $p>0.05$ ); however, the new cutoff $<1.75$ showed significant results $(\mathrm{p}=0.028)$ with a sensitivity and specificity of $84.62 \%$ and $52.17 \%$. The results reported by Nejad et al. [6] included patients who were nonventilated and showed a strong correlation between the IJV/CCA ratio and CVP at expiration ( $\mathrm{r}$ $=0.736)$ and at inspiration $(r=0.728)$, whereas our study showed a moderate correlation of the IJV/CCA diameter ratio at expiration with CVP $(r=0.439)$ in non-ventilated patients. So, a new cutoff for IJV/CCA $<1.75$ is recommended, with significant results.

Another study that was conducted by Bailey et al. [11] reported that the IJV/CCA ratio could predict the value of CVP. It was a pilot study that was conducted in the pediatric population. Our population included adult intensive care patients, so results cannot be generalized.

IJV, as a measure of hemodynamic status, has also been evaluated. Donahue et al. [12] reported a significant difference in IJV diameter in patients with a CVP of $<10$ or $\geqslant 10 \mathrm{~cm}_{2} \mathrm{O}$ and a significant correlation of IJV end-expiratory diameter and CVP $(r=0.82)$ was concluded. Our study reported a significant difference $(0.97$ versus $1.34 \mathrm{~cm})$ for IJV end-expiratory diameter in two groups and moderate correlation of IJV end-expiratory diameter and CVP $(r=0.544)$. Elsadek WM et al. [14] conducted a study on pediatric cardiac surgery patients to evaluate the IJV diameter and cross-sectional area to estimate CVP. It concluded a poor correlation as was in our study in patients who were on the ventilator.

IVC assessment is another non-invasive tool for the estimation of hemodynamic status. It has been studied widely and most accepted as the sonographic method of estimating CVP $[8,15]$. In comparison with the IJV/CCA ratio, the sonographic assessment of IVC is limited by difficulties in obese or surgical patients. Also, it needs extensive training. So, the IJV/CCA diameter ratio 
with a cutoff of $<1.75$ can predict CVP in these patients with less technical difficulties.

Respiratory fluctuations affect the venous return to the heart [16]. Our study assessed the IJV/CCA diameter ratio versus CVP relationship both at end inspiration and end expiration. A significant difference was found in non-ventilated patients $(p=0.032$ at the end of expiration and $p=0.143$ at the end of inspiration). These findings are different from Nejad et al.'s [6] who concluded that the correlation between the IJV/CCA ratio and CVP is not affected by respiration.

Our study has a few limitations. First, it is a single-centered study, so its results may not be generalized. Second, because of its small sample size, it may have an imprecise estimation of results and may not be highly applicable to a wide variety of populations. Third, the sonographic measurements are usually operator-dependent, which may lead to an alteration of measurements and results.

\section{Conclusions}

The assessment of volume status by the IJV/CCA diameter ratio with a sonographic device may be a useful, non-invasive alternative for a central venous catheterization with cutoff $<1.75$. However, further studies are needed to confirm the results of our study.

\section{Additional Information \\ Disclosures}

Human subjects: Consent was obtained by all participants in this study. Institutional Review Board and Ethics Committee, Shifa International Hospital issued approval IRB\#724-172-2016. After review of your amended study entitled as "Measurement of IJV/CCA diameter by ultrasound to estimate central venous pressure" by the IRB \& EC. The committee is pleased to APPROVE your study. Animal subjects: All authors have confirmed that this study did not involve animal subjects or tissue. Conflicts of interest: In compliance with the ICMJE uniform disclosure form, all authors declare the following: Payment/services info: All authors have declared that no financial support was received from any organization for the submitted work. Financial relationships: All authors have declared that they have no financial relationships at present or within the previous three years with any organizations that might have an interest in the submitted work. Other relationships: All authors have declared that there are no other relationships or activities that could appear to have influenced the submitted work.

\section{References}

1. Kosiak W, Swieton D, Piskunowicz M: Sonographic inferior vena cava/aorta diameter index, a new approach to the body fluid status assessment in children and young adults in emergency ultrasound-preliminary study. Am J Emerg Med. 2008, 26:320-325.

10.1016/j.ajem.2007.07.012

2. Murdoch SD, Cohen AT, Bellamy MC: Pulmonary artery catheterization and mortality in critically ill patients. Br J Anaesth. 2000, 85:611-615. 10.1093/bja/85.4.611

3. Kastrup M, Markewitz A, Spies C, Carl M, Erb J, Grosse J, Schirmer U: Current practice of hemodynamic monitoring and vasopressor and inotropic therapy in post-operative cardiac surgery patients in Germany: results from a postal survey. Acta Anaesthesiol Scand. 2007, 51:347-358. 10.1111/j.1399-6576.2006.01190.x

4. Stawicki SP, Braslow BM, Panebianco NL, Kirkpatrick JN, Gracias VH, Hayden GE, Dean AJ: Intensivist use of hand-carried ultrasonography to measure IVC collapsibility in estimating intravascular volume status: correlations with CVP. J Am Coll Surg. 2009, 209:55-61. 10.1016/j.jamcollsurg.2009.02.062

5. Kent A, Patil P, Davila V, et al.: Sonographic evaluation of intravascular volume status: can internal jugular or femoral vein collapsibility be used in the absence of IVC visualization?. 
Ann Thorac Med. 2015, 10:44-49.

6. Hossein-Nejad H, Mohammadinejad P, Ahmadi F: Internal jugular vein/common carotid artery cross-sectional area ratio and central venous pressure. J Clin Ultrasound. 2016, 44:312-318. 10.1002/jcu.22339

7. Malik A, Akhtar A, Saadat S, Mansoor S: Predicting central venous pressure by measuring femoral venous diameter using ultrasonography. Cureus. 2016, 8:e893. Accessed: Nov 23, 2016: https://www.cureus.com/articles/5823-predicting-central-venous-pressure-bymeasuring-femoral-venous-diameter-using-ul.... 10.7759/cureus.893

8. Ilyas A, Ishtiaq W, Assad S, et al.: Correlation of IVC Diameter and Collapsibility Index With Central Venous Pressure in the Assessment of Intravascular Volume in Critically Ill Patients. Cureus. 2017, 9:e1025. Accessed: February 12, 2017: https://www.cureus.com/articles/6380correlation-of-ivc-diameter-and-collapsibility-index-with-central-venous-pressur.... 10.7759/cureus. 1025

9. Busche C, Busch HJ, Michels G: Point-of-care sonography in emergency and intensive care medicine [Article in German]. Dtsch med Wochenschr. 2018, 143:161-164. 10.1055/s-0043115604

10. Hilbert T, Ellerkmann RK, Klaschik S, Putensen C, Thudium M: The use of internal jugular vein ultrasonography to anticipate low or high central venous pressure during mechanical ventilation. J Emerg Med. 2016, 50:581-587. 10.1016/j.jemermed.2015.11.033

11. Bailey JK, McCall J, Smith S, Kagan RJ: Correlation of internal jugular vein/common carotid artery ratio to central venous pressure: a pilot study in pediatric burn patients. J Burn Care Res. 2012, 33:89-92. 10.1097/BCR.0b013e318234d965

12. Donahue SP, Wood JP, Patel BM, Quinn JV: Correlation of sonographic measurements of the internal jugular vein with central venous pressure. Am J Emerg Med. 2009, 27:851-855. 10.1016/j.ajem.2008.06.005

13. Dellinger RP, Levy MM, Rhodes A, et al.: Surviving Sepsis Campaign: International guidelines for management of severe sepsis and septic shock. Crit Care Med. 2013, 41:580-637. 10.1097/CCM.0b013e31827e83af

14. Elsadek WM, Elaela AH, Nassar HM, Kamel MM, Mohamed AA, Ali HM: Sonographic evaluation of internal jugular vein diameter and cross-sectional area measurements in correlation with left ventricular end diastolic area as a tool for perioperative assessment of volume status in pediatric patients undergoing cardiac surgery. Anesth Essays Res. 2017, 11:453. 10.4103/0259-1162.194587

15. Zhang X, Luan H, Zhu P, Feng J, Cui J, Zhao Z: Does ultrasonographic measurement of the inferior vena cava diameter correlate with central venous pressure in the assessment of intravascular volume in patients undergoing gastrointestinal surgery?. J Surg Res. 2014, 191:339-343. 10.1016/j.jss.2014.04.043

16. Osada T, Katsumura T, Hamaoka T, Murase N, Naka M, Shimomitsu T: Quantitative effects of respiration on venous return during single knee extension-flexion. Int J Sports Med. 2002, 23:183-190. 10.1055/s-2002-23177 